\title{
Article \\ Influence of TP53 Mutation on Survival of Diffuse Large B-Cell Lymphoma in the CAR T-Cell Era
}

\author{
Edit Porpaczy ${ }^{1}\left(\right.$, Philipp Wohlfarth ${ }^{2}$, Oliver Königsbrügge ${ }^{1} \oplus$, Werner Rabitsch ${ }^{2}$, Cathrin Skrabs ${ }^{1}$, \\ Philipp Staber ${ }^{1}$, Nina Worel ${ }^{3}$, Leonhard Müllauer ${ }^{4}{ }^{\circledR}$, Ingrid Simonitsch-Klupp ${ }^{4}$, Christoph Kornauth ${ }^{4}$, \\ Johannes Rohrbeck ${ }^{4}$, Ulrich Jaeger ${ }^{1}$ and Ana-Iris Schiefer ${ }^{4, *}$
}

1 Department of Internal Medicine I, Division of Hematology and Hemostaseology, Medical University of Vienna, 1090 Vienna, Austria; edit.porpaczy@meduniwien.ac.at (E.P.); oliver.koenigsbruegge@meduniwien.ac.at (O.K.); cathrin.skrabs@meduniwien.ac.at (C.S.); philipp.staber@meduniwien.ac.at (P.S.); ulrich.jaeger@meduniwien.ac.at (U.J.)

2 Department of Internal Medicine I, Hematopoietic Stem Cell Transplantation Unit, Medical University of Vienna, 1090 Vienna, Austria; philipp.wohlfarth@meduniwien.ac.at (P.W.); werner.rabitsch@meduniwien.ac.at (W.R.)

3 Department of Blood Group Serology and Transfusion Medicine, Medical University of Vienna, 1090 Vienna, Austria; nina.worel@meduniwien.ac.at

4 Department of Pathology, Medical University of Vienna, 1090 Vienna, Austria; leonhard.muellauer@meduniwien.ac.at (L.M.); ingrid.simonitsch-klupp@meduniwien.ac.at (I.S.-K.); christoph.kornauth@meduniwien.ac.at (C.K.); johannes.rohrbeck@meduniwien.ac.at (J.R.)

check for updates

Citation: Porpaczy, E.; Wohlfarth, P.; Königsbrügge, O.; Rabitsch, W.; Skrabs, C.; Staber, P.; Worel, N.; Müllauer, L.; Simonitsch-Klupp, I.; Kornauth, C.; et al. Influence of TP53 Mutation on Survival of Diffuse Large B-Cell Lymphoma in the CAR T-Cell Era. Cancers 2021, 13, 5592. https://doi.org/10.3390/ cancers13225592

Academic Editors:

Cristina Papayannidis and Francesco Bertolini

Received: 29 September 2021 Accepted: 5 November 2021 Published: 9 November 2021

Publisher's Note: MDPI stays neutral with regard to jurisdictional claims in published maps and institutional affiliations.

Copyright: () 2021 by the authors. Licensee MDPI, Basel, Switzerland. This article is an open access article distributed under the terms and conditions of the Creative Commons Attribution (CC BY) license (https:// creativecommons.org/licenses/by/ $4.0 /)$.
* Correspondence: ana-iris.schiefer@meduniwien.ac.at

Simple Summary: The genetic landscape of diffuse large B-cell lymphoma (DLBCL) is heterogenous. So far, detailed studies about TP53 mutations in DLBCL treated with anti-CD19 chimeric antigen receptor T-cell (CAR T cells) therapy are still missing. Chemotherapy resistance is one of the challenges in TP53 mutated tumors. New immunomodulatory agents, such as different inhibitors or CAR T cells, have shown durable responses in refractory/relapsed DLBCL in recent years. Although our CAR T cell treated cohort was small, we aimed to investigate the influence of TP53 mutations on overall survival of patients treated with CAR T cells compared to DLBCL patients without CAR T-cell therapy. Identification of risk factors for treatment failure may aid in choosing the most promising treatment in every setting.

Abstract: Refractory/relapsed diffuse large B-cell lymphoma (DLBCL) is associated with poor outcome. The clinical behavior and genetic landscape of DLBCL is heterogeneous and still not fully understood. TP53 mutations in DLBCL have been identified as markers of poor prognosis and are often associated with therapeutic resistance. Chimeric antigen receptor T-cell therapy is an innovative therapeutic concept and represents a game-changing therapeutic option by supporting the patient's own immune system to kill the tumor cells. We investigated the impact of TP53 mutations on the overall survival of refractory/relapsed DLBCL patients treated with comparable numbers of therapy lines. The minimum number of therapy lines was 2 (median 4), including either anti-CD19 CAR T-cell therapy or conventional salvage therapy. A total of 170 patients with DLBCL and high-grade B-cell lymphoma with MYC, BCL2, and/or BCL6 rearrangements (DHL/THL), diagnosed and treated in our hospital between 2000 and 2021, were included. Twenty-nine of them received CAR T-cell therapy. TP53 mutations were found in 10/29 $(35 \%)$ and $31 / 141(22 \%)$ of patients in the CAR T-cell and conventional groups, respectively. Among the 141 patients not treated with CAR T cells, TP53 mutation was an independent prognostic factor for overall survival (OS) (median 12 months with TP53 vs. not reached without TP53 mutation, $p<0.005$ ), but in the CAR T cell treated group, this significance could not be shown (median OS 30 vs. 120 months, $p=0.263$ ). The findings from this monocentric retrospective study indicate that TP53 mutation status does not seem to affect outcomes in DLBCL patients treated with CAR T-cell therapy. Detailed evaluation in large cohorts is warranted.

Keywords: DLBCL; anti-CD19 CAR T cells; TP53 mutation; TP53 polymorphism; overall survival 


\section{Introduction}

Diffuse large B-cell lymphoma (DLBCL) is an aggressive non-Hodgkin lymphoma (NHL) with heterogenous clinical behavior. Different genetic alterations influence clinical course and treatment response [1-3]. Besides genes involved in the B-cell receptor (BCR) signaling pathway, which is specific for lymphomas, other recurrent oncogenic mutations have been described in DLBCL [1-4]. Between five and ten percent of DLBCL have concurrent rearrangements of $M Y C, B C L 2$, and/or $B C L 6$ and are now recognized as a distinct entity in the 2016 WHO classification of lymphoid neoplasms as 'high-grade B-cell lymphoma with $M Y C, B C L 2$, and/or BCL6 rearrangements (DHL/THL)'.

TP53 is a tumor suppressor gene and plays an important role in the cell cycle and proliferation. One of its main functions is to induce apoptosis in DNA damaged cells. Mutations in the TP53 gene abrogate genetic stability and lead to uncontrolled proliferation of cancer cells [5]. TP53 mutations are found in approximately $20-30 \%$ of DLBCL patients [2,6-8]. The role of the TP53 mutation as a negative prognostic factor is well established in many malignancies, including DLBCL. Xu-Monette et al. have shown a predictive role for TP53 in both the GCB and non-GCB DLBCL patients treated with rituximab, cyclophosphamide, doxorubicin, vincristine, and prednisolone (R-CHOP) [9].

Frequent occurrence of TP53 alterations has been shown in DLBCL at relapse after therapy with R-CHOP, even if TP53 mutations were absent at the initial diagnosis, suggesting a tendency towards mutations under immunochemotherapy [10].

Additionally, the presence of TP53 mutations has been shown to be associated with drug resistance in several studies [11-13]. In DLBCL, TP53 mutations are associated with dismal prognosis due to therapy refractoriness $[7,9,10,14-17]$. Several molecular mechanisms of drug resistance on the basis of TP53 mutations have been described and were summarized by Hientz et al. [13].

The treatment of DLBCL is challenging. High-dose platin-containing agents in combination with other cytotoxic agents followed by autologous stem cell transplantation (ASCT) is still the established standard treatment to cure relapsed or refractory patients.

In recent years, chimeric antigen receptor T-cell (CAR T-cell) therapy has been shown to be a promising therapy in refractory/relapsed DLBCL $[18,19]$. CAR T-cell therapy has a completely different mechanism to eliminate tumor cells compared to cytotoxic agents. Patients' autologous T cells are manufactured to gain the ability to target and kill lymphoma cells by gammaretroviral or lentiviral transduction of CARs against CD19, which is expressed on the surface of DLBCL cells. After infusion, CAR T cells recognize and destroy CD19-expressing cells. Compared with conventional salvage treatment, CAR T-cell therapy showed a clear benefit regarding survival in DLBCL [18]; however, more data from large trials are needed. Little is known about the impact of genetic alterations in lymphoma patients treated with CAR T cells.

The aim of the study was to investigate the impact of TP53 mutations on overall survival in a cohort of patients with refractory/relapsed DLBCL and DHL/THL, comparing patients who received CAR T-cell therapy to control patients with conventional relapse therapies. Here we present the first preliminary data in a small DLBCL and DHL/THL cohort treated with anti-CD19 CAR T cells.

\section{Materials and Methods}

Patients: For this retrospective study, we included 170 patients with refractory/relapsed DLBCL and DHL/THL, treated either with anti-CD19 CAR T-cell therapy or as a control group treated with conventional therapy $(\mathrm{N}=29$ vs. 141). All patients received rituximab plus cyclophosphamide, doxorubicin, vincristine, and prednisone (R-CHOP) as first line therapy. In the control group, platin-containing regiments combined with rituximab were used in each case as second line salvage therapy. In the CAR T cell group, 22 patients received platin-based second line treatment; 7 patients received other second line treatments (bendamustine, gemcitabine, or venetoclax); and all 29 patients received combination therapy with antibodies. Third or later line therapies included antibodies (rituximab, 
obinotuzumab, polatuzumab), conventional cytotoxic agents (gemcitabine, bendamustine, pixantrone), and small molecule inhibitors (f.e., ibrutinib, idelalisib, revlimid, venetoclax, selinexor), alone or in combination with radiation. In the control group, none of the patients received CAR $T$ cells at any time.

Inclusion criteria were: (1) refractory or relapsed DLBCL or DHL/THL with at least two previous therapy lines; (2) including rituximab-containing treatment; (3) diagnosed and treated at our institution since 2000; (4) 18 years of age or older; (5) known detailed medical history. Transplant- and human immunodeficiency virus (HIV)-associated lymphomas were excluded. Clinical data, including medical history, date of diagnosis, clinical stage [20] according to Ann-Arbor classification, cell of origin (COO) according to the Hans algorithm [21], double hit protein expression score (DHS), TP53 mutations, MYC and BCL2 translocations, type and duration (including number of cycles) of treatments, date and quality of response, date of relapse, date of death including cause of death, and observation time, were collected. All cases were reviewed by three independent pathologists, and diagnoses were stated according to the 2016 WHO classification [22]. Patients were followed until June 2021 or until death, whichever occurred first.

Immunohistochemistry (IHC): IHC was performed on formalin-fixed, paraffinembedded sections on an automated platform (Leica Bond III Immunostainer, Leica Biosystems, Nussloch, Germany) using routine protocols. Antibody Clone DO-7, DAKO, Glostrup, Denmark was used for p53 staining, which was interpreted as positive if at least $30 \%$ of tumor cells were moderately to strongly positive in a sheetlike, diffuse pattern within the whole tumor tissue or at least within parts of the tumor. For BCL2 and MYC staining, the following antibodies were used: BCL2 (Clone 124, DAKO, DK-2600 Glostrup, Denmark); MYC (Clone E121, Epitomics, Burlingame, CA, USA). Cut-off values for BCL2 and MYC were $50 \%$ and $40 \%$, respectively.

Interphase FISH analysis: FISH was performed on formalin-fixed, paraffin-embedded tissue according to manufacturer recommendations. The following probes were used: LSI MYC Dual Color, Break Apart Rearrangement Probe (Metasystems, Altlussheim, Germany); LSI BCL2 Dual Color, Break Apart Rearrangement Probe (Abbott, North Chicago, IL, USA); and LSI BCL6 Dual Color, Break Apart Translocation Probe (Kreatech, Leica Biosystems, Nussloch, Germany). In each case, a total of 200 interphase nuclei were counted. The cut-off level for positivity was determined at $10 \%$ of nuclei showing aberrant hybridization signals.

Sequencing of TP53: TP53 mutation is associated with increased p53 protein expression, and TP53 mutational status was assessed in all p53 IHC-positive cases in the control group. TP53 sequencing was performed using an ABI BigDye ${ }^{\mathrm{TM}}$ Terminator version 1.1 Cycle Sequencing Kit (Thermo Fisher Scientific, Waltham, MA, USA). Sequencing analyses covered exons 4 to 11 and flanking intron regions. Purified DNA fragments were run on an ABI 330 Genetic Analyzer. Sequences were analyzed using the SeqScape analysis software program versions 2.5 and 2.7 (Applied Biosystems, Thermo Fisher Scientific, Waltham, MA, USA).

NGS: Tumor tissues of patients receiving CAR T cells were analyzed by next-generation sequencing. DNA was extracted from paraffin-embedded tissue blocks with the QIAamp Tissue Kit $^{\mathrm{TM}}$ (Quiagen, Hilden, Germany). DNA quantification was performed with the Qubit Assay Kit (Thermo Fisher Scientific). The DNA library was prepared with multiplex polymerase chain reaction with the DNA Oncomine ${ }^{\mathrm{TM}}$ Comprehensive Panel v3 (Ion Torrent, Thermo Fisher Scientific), covering 161 genes, including full gene TP53 (a list of analyzed genes is provided in Supplementary Materials; Table S1). After barcode adaption and quantification of the DNA library (Ion TaqMan ${ }^{\mathrm{TM}}$ Library Quantitation Kit, Thermo Fisher Scientific), template preparation was carried out with the Ion Chef ${ }^{\mathrm{TM}}$ System, where template-positive Ion Sphere ${ }^{\mathrm{TM}}$ Particles were generated and amplified and an Ion $530^{\mathrm{TM}}$ Chip was loaded. Sequencing was performed with an Ion S5 ${ }^{\mathrm{TM}}$ Sequencer (Thermo Fisher Scientific). Sequencing data were analyzed using Variant Caller ${ }^{\mathrm{TM}}$ and Ion Reporter ${ }^{\mathrm{TM}}$ (both Thermo Fisher Scientific). 
Statistical methods: Statistical analysis was performed using IBM SPSS Statistics 27.0.1.0 (IBM Corporation, Armonk, NY, USA) software. The distribution of categorical variables between groups was performed with the chi-squared test, and continuous variables were compared with the Mann-Whitney U test. Normality was assessed by a Q-Q plot. Kaplan-Meier analysis was performed to assess overall survival (OS) and a log-rank test for a comparison of survival between groups. The OS was calculated from the date of diagnosis to the date of all-cause death. We considered $p$-values $(p)$ of $<0.05$ (2-sided) statistically significant. Cases with unknown TP53 status were excluded.

\section{Results}

\subsection{Patients}

All refractory/relapsed DLBCL and DHL/THL patients who received anti-CD19 CAR T cells $(N=29)$ at our institute were included in this study. The control group $(N=141)$ consisted of refractory/relapsed DLBCL and DHL/THL patients with at least two rituximab-containing therapy lines and known TP53 status either within the framework of routine work-up or from our patient cohort already published [8]. Due to the known prognostic value of TP53 mutation shown by data from the literature $[10,16,17,23]$ and from our own study group [8], TP53 mutational analyses have been frequently performed at our institute since 2010 as part of the diagnostic routine work-up for relapsed/refractory DLBCL and DHL/THL. Initially, 202 potentially eligible control patients were included. Sixty-one patients of the control group were excluded due to insufficient clinical information. We finally ended up with a definitive study cohort of 170 patients, 29 thereof treated with CAR $\mathrm{T}$ cells and 141 controls. Both cohorts comprised patients of comparable age (CAR T cell patients vs. control patients: median ages at diagnosis, 54.83 vs. 59.76 years, $p=0.123$ ) and gender ( $44.8 \%$ females and $55.2 \%$ males vs. $41.8 \%$ females and $58.2 \%$ males, $p=0.838$ ) distribution. Nine (31.0\%) out of 29 vs. $47(33.3 \%)$ out of 141 patients had primary refractory DLBCL in the CAR T cell group vs. controls. The control patients received 2-15 therapy lines (median 5); the CAR T cell group received 2-13 (median 3) prior to CAR T-cell therapy. Conventional treatment consisted of platin-containing therapy in the second line. In the CAR T cell group, nine (31.0\%) patients had primary refractory disease, and $20(68.96 \%)$ patients relapsed after achieving complete remission with R-CHOP. Forty-seven (33.3\%) out of 141 patients had primary refractoriness, and 94 (66.6\%) relapsed in the controls. The median time from initiation of the first salvage treatment to CAR $\mathrm{T}$ cell infusion was 10.7 months.

TP53 mutations were found in $34.5 \%$ of the CAR T cell patients and in $22 \%$ of the controls, indicating enrichment of poor prognostic patients in the CAR T cell cohort. Furthermore, $7.9 \%$ of the CAR T cell patients and $56 \%$ of the control group died within the observation period.

Patient clinical and demographic characteristics are presented in Table 1.

\subsection{Pathohistological Characteristics of the CAR T Cell Cohort}

FISH analyses for $M Y C, B L C 2$, and BCL6 rearrangement were available for 27 (out of 29) patient samples. Eight (27.6\%) patients had rearrangement of the MYC gene; two (6.9\%) patients had additional translocations of the BCL2 gene and one (3.5\%) of the BCL6 gene locus. Two (6.9\%) patients were triple hits with rearrangements of MYC, BCL2, and BCL6. According to the WHO classification [22], a total of five (17.2\%) patients were, therefore, reclassified as aggressive B-cell lymphoma with $M Y C, B C L 2$, and/or BCL6 rearrangements (DHL/THL).

Immunohistochemistry for the BCL2 and MYC proteins was performed in 26 out of 29 CAR T samples. Nineteen (65.5\%) patients expressed both proteins according to a double hit expression score of 2 [23] (double expressor lymphoma (DEL)); 7 (24.1\%) expressed only the BCL2 protein.

According to the Hans algorithm [21], 16 patients showed a non-GCB phenotype, and 11 were categorized as GCB type. 
Table 1. Patient characteristics.

\begin{tabular}{|c|c|c|c|c|c|c|c|}
\hline \multirow{3}{*}{ Characteristics } & \multicolumn{2}{|c|}{ Whole Cohort } & \multicolumn{2}{|c|}{ CAR T Cells } & \multicolumn{2}{|c|}{ Controls } & \multirow[b]{2}{*}{$p$-Value } \\
\hline & No & $\%$ & No & $\%$ & No & $\%$ & \\
\hline & 170 & 100 & 29 & 17.1 & 141 & 82.9 & \\
\hline \multicolumn{8}{|l|}{ Gender } \\
\hline Female & 72 & 42.4 & 13 & 44.8 & 59 & 41.8 & 0.838 \\
\hline Male & 98 & 57.6 & 16 & 55.2 & 82 & 58.2 & 0.838 \\
\hline Median age at diagnosis & 56.99 & $(19-95)$ & 54.83 & $(31-79)$ & 59.76 & (19-95) & 0.123 \\
\hline Stage = III-IV & 107 & 62.9 & 10 & 34.5 & 97 & 68.8 & $<0.001$ \\
\hline Extranodal & 109 & 64.1 & 10 & 34.5 & 99 & 70.2 & $<0.001$ \\
\hline Transformed & 21 & 12.4 & 5 & 17.2 & 16 & 11.3 & 0.553 \\
\hline \multicolumn{8}{|l|}{$\mathrm{COO}$} \\
\hline Non-GCB & 63 & 36.8 & 16 & 55.2 & 47 & 33.3 & 0.035 \\
\hline GCB & 93 & 55 & 11 & 37.9 & 82 & 58.2 & 0.064 \\
\hline NA & 14 & 8.2 & 2 & 6.9 & 12 & 8.5 & 0.999 \\
\hline DEL & 71 & 41.8 & 19 & 65.5 & 52 & 36.9 & 0.003 \\
\hline TP53+ & 41 & 24.1 & 10 & 34.5 & 31 & 22.0 & 0.804 \\
\hline MYC+ & 72 & 42.4 & 8 & 27.6 & 64 & 45.4 & 0.055 \\
\hline$B C L 2+$ & 41 & 24.1 & 4 & 13.8 & 37 & 26.2 & 0.121 \\
\hline DHL/THL & 35 & 20.6 & 5 & 17.2 & 30 & 21.3 & 0.628 \\
\hline $\begin{array}{l}\text { Primary refractory } \\
\text { DLBCL }\end{array}$ & 56 & 32.9 & 9 & 31.0 & 47 & 33.3 & 0.833 \\
\hline Relapsed DLBCL & 114 & 67.1 & 20 & 69.0 & 94 & 66.7 & 0.833 \\
\hline Death & 90 & 52.9 & 11 & 37.9 & 79 & 56.0 & 0.102 \\
\hline
\end{tabular}

COO: cell of origin; non-GCB: non-germinal center B-cell-like; GCB: germinal center B-cell-like; NA: not applicable DEL: double expressor lymphoma (BCL2 and MYC protein expression); TP53+: presence of TP53 mutation; MYC+: presence of $M Y C$ translocation; BCL2+: presence of BCL2 translocation; DHL/THL: double hit lymphoma/triple hit lymphoma. The $p$-values for comparison of distributions were calculated with the Mann -Whitney $\mathrm{U}$ test for continuous variables and chi-squared test for categorical variables.

\subsection{Pathohistological Characteristics of the Control Group}

FISH was performed in 130 out of 141 tumor samples from the control group. Sixtyfour (45.4\%) tumors showed a MYC rearrangement; 29 (20.57\%) samples thereof had an additional BCL2 rearrangement (hence belonging to the DHL category); one lymphoma sample revealed translocations in MYC, BCL2, and BCL6 (THL). Fifty-two (36.9\%) tumors expressed both the MYC and BCL2 proteins (DEL). Fifty-six (39.7\%) were positive for only one of either MYC or BCL2. In detail, 66 (46.8\%) patients expressed MYC and $100(70.9 \%)$ patients the BCL2 protein. Forty-seven (33.3\%) samples belonged to the non-GCB group; $82(58.2 \%)$ were categorized as GCB. According to the Hans algorithm [21], 47 patients showed a non-GCB phenotype, and 82 were categorized as GCB type.

\subsection{TP53 Mutations}

From the CAR T cell cohort, tumor samples from 22 patients were sequenced by NGS. Analyses were done from the latest biopsy sample taken immediately before the start of treatment. From the remaining seven patients, material was not sufficient for molecular analyses.

Within the control group, screening for TP53 mutations was performed by immunohistochemistry, and patients with $>30 \%$ strongly positive tumor cells were further sequenced: 54 by Sanger sequencing covering exons $4-11$, seven patient samples by NGS. 
In summary, TP53 mutations were detected in 41 patients and 44 patient samples (three patients from the control group had two concordant TP53 mutations in different exons (Table 2)).

Table 2. TP53 Mutations.

\begin{tabular}{|c|c|c|c|c|c|c|}
\hline Diagnosis & Cohort & Sequencing & Mutation & Exon & Effect & TA Class \\
\hline DLBCL & Control & Sanger & G266V & Exon8 & Missense & Nonfunctional \\
\hline DLBCL & Control & Sanger & Y205C & Exon6 & Missense & Nonfunctional \\
\hline DHL & Control & Sanger & M237I & Exon7 & Missense & Nonfunctional \\
\hline DLBCL & Control & Sanger & G245A & Exon7 & Missense & Nonfunctional \\
\hline DHL & Control & Sanger & F134L & Exon5 & Missense & Nonfunctional \\
\hline DLBCL & Control & Sanger & V143E & Exon5 & Missense & Nonfunctional \\
\hline DLBCL & Control & Sanger & $\begin{array}{l}\text { R248Q } \\
\text { R267W }\end{array}$ & $\begin{array}{l}\text { Exon7 } \\
\text { Exon8 }\end{array}$ & $\begin{array}{l}\text { Missense } \\
\text { Missense }\end{array}$ & $\begin{array}{l}\text { Nonfunctional } \\
\text { Nonfunctional }\end{array}$ \\
\hline DHL & Control & Sanger & R248Q & Exon7 & Missense & Nonfunctional \\
\hline DLBCL & Control & Sanger & R280S & Exon8 & Missense & Nonfunctional \\
\hline DLBCL & Control & Sanger & $\begin{array}{l}\text { L194P } \\
\text { M246V }\end{array}$ & $\begin{array}{l}\text { Exon6 } \\
\text { Exon7 }\end{array}$ & $\begin{array}{l}\text { Missense } \\
\text { Missense }\end{array}$ & $\begin{array}{l}\text { Nonfunctional } \\
\text { Nonfunctional }\end{array}$ \\
\hline DHL & Control & Sanger & R248Q & Exon7 & Missense & Nonfunctional \\
\hline DLBCL & Control & Sanger & R248Q & Exon7 & Missense & Nonfunctional \\
\hline DLBCL & Control & Sanger & G245S & Exon7 & Missense & Nonfunctional \\
\hline DLBCL & Control & Sanger & Y234S & Exon7 & Missense & Nonfunctional \\
\hline DLBCL & Control & Sanger & $\mathrm{R} 273 \mathrm{H}$ & Exon8 & Missense & Nonfunctional \\
\hline DLBCL & Control & Sanger & Q331X & Exon9 & Nonsense & $\mathrm{Na}$ \\
\hline DLBCL & Control & Sanger & Y220C & Exon6 & Missense & Nonfunctional \\
\hline DLBCL & Control & Sanger & $\mathrm{Y} 236 \mathrm{H}$ & Exon7 & Missense & Nonfunctional \\
\hline DLBCL & Control & Sanger & G245S & Exon7 & Missense & Nonfunctional \\
\hline DHL & Control & Sanger & W53L & Exon4 & Missense & Functional \\
\hline $\mathrm{DHL}$ & Control & Sanger & E286G & Exon8 & Missense & Nonfunctional \\
\hline DLBCL & Control & Sanger & $\begin{array}{l}\text { R175H } \\
\text { G262V }\end{array}$ & $\begin{array}{l}\text { Exon5 } \\
\text { Exon8 }\end{array}$ & $\begin{array}{l}\text { Missense } \\
\text { Missense }\end{array}$ & $\begin{array}{l}\text { Nonfunctional } \\
\text { Nonfunctional }\end{array}$ \\
\hline DLBCL & Control & Sanger & N239D & Exon7 & Missense & Nonfunctional \\
\hline DLBCL & Control & Sanger & $\mathrm{H} 179 \mathrm{Y}$ & Exon5 & Missense & $\begin{array}{l}\text { Partially } \\
\text { Functional }\end{array}$ \\
\hline DHL & Control & NGS & $\mathrm{R} 273 \mathrm{H}$ & Exon8 & Missense & Nonfunctional \\
\hline THL & Control & NGS & $\mathrm{R} 175 \mathrm{H}$ & Exon5 & Missense & Nonfunctional \\
\hline DLBCL & Control & NGS & H214R & Exon6 & Missense & Nonfunctional \\
\hline DLBCL & Control & Sanger & G187S & Exon5 & Missense & Functional \\
\hline
\end{tabular}


Table 2. Cont.

\begin{tabular}{ccccccc}
\hline Diagnosis & Cohort & Sequencing & Mutation & Exon & Effect & TA Class \\
\hline DLBCL & Control & Sanger & S315F & Exon9 & Missense & Functional \\
\hline DHL & Control & Sanger & V272E & Exon8 & Missense & Nonfunctional \\
\hline DLBCL & Control & Sanger & R282W & Exon8 & Missense & Nonfunctional \\
\hline THL & CAR T & NGS & V157G & Exon5 & Missense & Nonfunctional \\
\hline DLBCL & CAR T & NGS & C242S & Exon7 & Missense & Nonfunctional \\
\hline THL & CAR T & NGS & C137W & Exon5 & Missense & Partially \\
& & NGS & R248Q & Exon7 & Missense & Nonfunctional \\
\hline DLBCL & CAR T & NGS & C176* & Exon5 & Nonsense & na \\
\hline DLBCL & CAR T & NGS & Y234C & Exon7 & Missense & Nonfunctional \\
\hline DHL & CAR T & NGS & Q167* & Exon5 & Nonsense & na \\
\hline DLBCL & CAR T & NGS & R273H & Exon8 & Missense & Nonfunctional \\
\hline DLBCL & CAR T & NGS & F113del & Exon4 & Na & Na \\
\hline DLBCL & CAR T & NGS & Q331* & Exon9 & Nonsense & Na \\
\hline DLBCL & CAR T & NGS & Nar
\end{tabular}

DLBCL: diffuse large B-cell lymphoma; DHL: double hit lymphoma (MYC and BCL2 or BCL6 translocation) THL: triple hit lymphoma (MYC + BCL2 + BCL6 translocation); NGS: next generation sequencing, TA: transactivational activity, NA: not applicable.

TP53 mutations were found in $10(34.5 \%)$ of the CAR T cell tumors and in $31(22 \%)$ patients from the control group, respectively.

Within the DHL/THL patient group, TP53 mutations were detectable in three $(60 \%)$ out of five DHL/THLs in the CAR T cell cohort (one sample did not reveal TP53 mutation by NGS, and in one sample, sequencing could not be performed). From the 16 DHL/THL (out of 30) samples within the control group, TP53 mutations were detected in nine patients $(56.3 \%)$.

The great majority of the mutations detected were missense mutations $(N=39,95.1 \%)$, followed by four $(9.8 \%)$ nonsense mutations resulting in truncated proteins; one (2.4\%) sample from the CAR T cell cohort had an in-frame deletion of 3 bases in exon 4 . Except for one variant, all mutations were found in the DNA-binding domain, the majority in exon 7 $(N=15,36.6 \%)$. The most common mutation was R248Q $(N=5,12.2 \%)$.

\subsection{Influence of TP53 Mutations on Overall Survival}

The mean observation period (date of diagnosis to last follow-up) was 49.49 months (range: 1 month to 321 months; standard deviation: 53.167 months).

Among the controls, the presence of TP53 mutations was associated with a significantly ( $p=0.005$ ) worse overall survival (median OS with TP53 mutations: 12.55 months, $95 \%$ confidence interval (95\% CI): $9.167-15.933$ vs. not reached with TP53 wild type). This influence of TP53 mutations could not be shown in the CAR T cell treated patients (median survival: 30.88 vs. 120.640 months, $p=0.263$ ) (Figures 1 and 2). 


\section{Overall Survival of Controls}

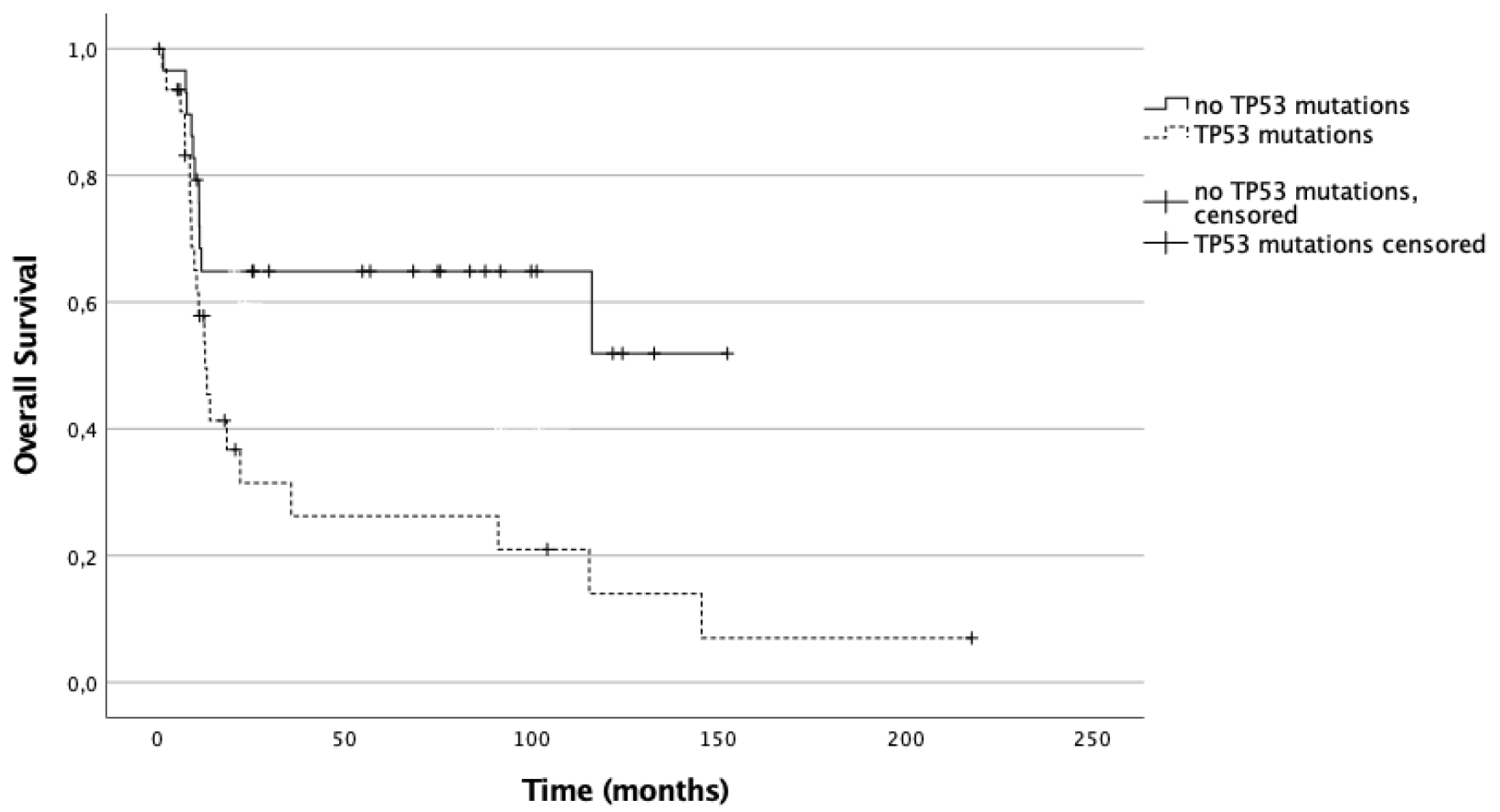

Figure 1. Overall survival of controls.

Overall Survival of Patients Treated with CAR T cells

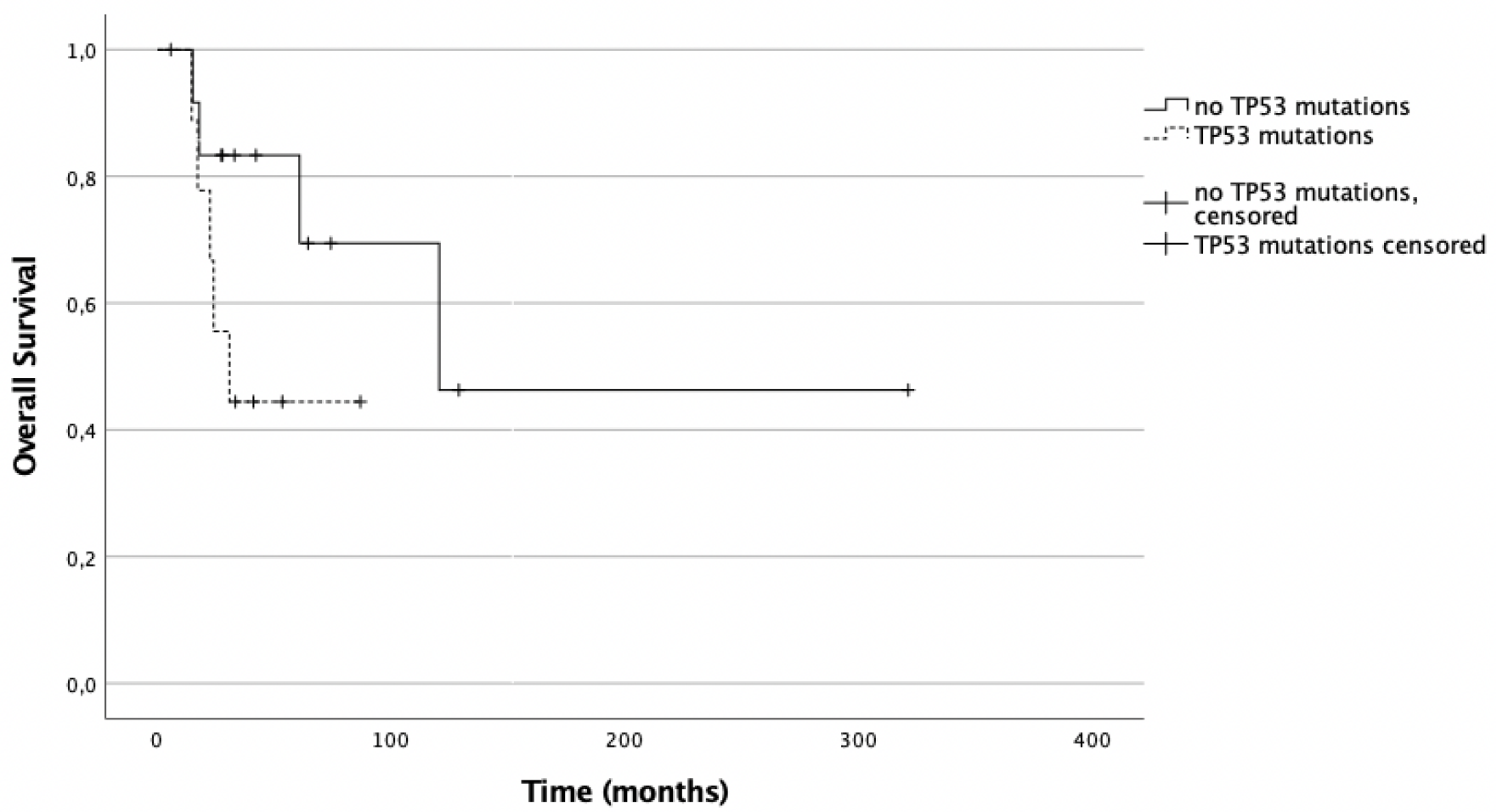

Figure 2. Overall survival of patients treated with CAR T cells. 


\section{Discussion}

DLBCL is a heterogenous disease with complex biological behavior. Relapsed or refractory DLBCL is associated with poor survival, and despite the rapid development of novel treatment strategies, management of those patients is still challenging for physicians. The negative prognostic impact of TP53 mutation and its association with drug resistance is well known in many malignancies, including DLBCL [10,15]; however, the prognostic value of TP53 mutations in refractory DLBCL patients receiving CAR T cells is still undefined. In this study, comprising only a small cohort of patients receiving CAR T cells, TP53 lost its significance as a negative prognostic marker, indicating that CAR T cells might equalize-at least to some extent-the adverse effect of TP53 mutations.

TP53 has been one of the best described tumor suppressor genes since its recognition in 1989. A nonsynonymous TP53 mutation is the most common reason for inactivation of p53. Point mutations comprise over $90 \%$ of TP53 alterations in hematological malignancies; almost $80 \%$ are missense mutations. In our study, missense mutations even accounted for 95\% of detected TP53 alterations.

TP53 displays its function via transcription-dependent and -independent activation. For both mechanisms, the DNA-binding domain plays an important role. Thus, most TP53 deleterious mutations occur in the DNA-binding domain, which covers exons 4-8. Except one variant, all mutations in our study were found in the DNA-binding domain, the majority thereof in exon $7(N=15)$. The most common mutation was R248Q $(N=5)$, followed by $\mathrm{R} 273 \mathrm{H}$, the latter found in three tumor samples. The codons 248 and 273 bind to major and minor grooves of DNA and belong to the TP53 mutation hot spots found in most human malignancies. The effect on p53 transcription function can be determined from the International Agency for Research on Cancer (IARC) TP53 database [24]. Accordingly, 34 of the missense mutations had no transactivation function; two were partially functional, and three were functional. This is in line with data from the literature, where the vast majority of TP53 mutations are classified as loss of function mutations in DLBCL [9].

Besides the cancer preventing role of TP53, its involvement in chemotherapy resistance has been described in many TP53-mutated tumors, causing dismal prognosis [25-37]. Even polymorphisms of TP53 have been shown to be involved in drug resistance [29]. In DLBCL, little is known about the biological effect of TP53 polymorphism. Of note, many of our patients had the TP53 polymorphism R72P either as a sole aberration $(\mathrm{N}=21)$ or concurrent with an actual pathogenic TP53 mutation ( $\mathrm{N}=22$, data not shown). Due to its yet unknown significance, this polymorphism was assigned as negative for TP53 mutation in our study. Chemotherapy resistance is a considerable problem in refractory lymphomas. Before the availability of CAR T cell therapy and other biological treatments such as BTKand other inhibitors, relapsed and refractory DLBCL patients had very limited therapy options, e.g., high-dose platin-containing regiments followed by autologous stem cell transplantation and, in rare cases, allogeneic stem cell transplantation where available for fit patients. Patients not eligible for high-dose chemotherapy were usually treated only in a palliative setting, with the goal to decelerate tumor progression and to raise life expectancy. For patients that demonstrate refractory disease to second line chemoimmunotherapy, outcomes have historically been dismal [38,39]. Even allogeneic transplantation performs very poorly if patients are not responding at the time of transplant. CAR T-cell therapy, on the other hand, is effective even in chemorefractory disease, which is a significant advantage. However, whether TP53 status affects CAR T cell outcomes in DLBCL is unknown. The implementation of CAR T cells has revolutionized the therapeutic landscape in DLBCL. Compared with conventional chemotherapeutics, CAR T cells operate on a completely different basis. Besides the direct cytotoxic activity, CAR T cells have been shown to modulate the tumor microenvironment $[40,41]$. It is conceivable that treatment with CAR T cells might overcome the adverse effect of TP53 mutations.

Many trials of CAR T-cell therapy have shown strong and durable responses in relapsed/refractory DLBCL disease [19,20,42,43]. Three FDA approved CAR T cell products (axicabtagene ciloleucel, tisagenlecleucel, and lisocabtagene maraleucel) are currently 
available for $\mathrm{r} / \mathrm{r}$ DLBCL: axi-cell with an overall response (OR) rate of 83\% (58\% complete remission (CR) rate) [20] and tisa-cell with an OR of $52 \%$ and a CR rate of $40 \%$ [43]. Currently, many studies worldwide are investigating CAR T-cell treatment in DLBCL in different settings, including comparison of both autologous stem cell and CAR T-cell therapies in relapsed/refractory lymphomas.

The prognostic value of TP53 mutations in refractory DLBCL patients receiving CAR $\mathrm{T}$ cells is still undefined. There are also only limited data on the efficacy of CAR T-cell therapy in patients with TP53 mutations in another B-cell neoplasm, namely, B-ALL, where this novel treatment was first implemented. In a phase 1/2 CAR T-cell therapy study comprising 115 patients with refractory/relapsed B-ALL, TP53 mutation was an independent indicator of poor prognosis. OS and leukemia-free survival (LFS) at 6 months were significantly lower in TP53 mutated patients (OS: $51.9 \%$ vs. $89 \%$; LFS: $42.4 \%$ vs. $82.6 \%$ ) [44]. However, in the same study, no differences in CR rates at day 30 after CAR T-cell therapy were detected, indicating susceptibility of lymphoma/leukemia cells for CAR T cells. Similar results were obtained by Pan et al. [45]. CAR T-cell therapy was indeed able to overcome the adverse impact of TP53 mutation to induce remission [46,47]; however, DFS and relapse rate were negatively influenced by TP53 mutation [45]. TP53 mutations were detected in $25.9 \%$ (14/56) of $\mathrm{r} / \mathrm{r}$ B-ALLs treated with CD19 CAR T cells followed by consolidation with allogeneic hematopoietic stem cell transplantation or CD22 CAR T-cell infusion. The frequency of TP53 mutation at relapse after CD19 CAR T-cell therapy was $66.7 \%(8 / 12)$. The anti-CD19 chimeric antigen receptor T-cell therapy KTE-X19 has shown efficacy in in patients with relapsed or refractory mantle-cell lymphoma, even in subgroups with high-risk features. TP53 mutated patients $(N=6)$ had objective response rates comparable to TP53 unmutated patients $(N=30)$ [48].

TP53 mutations were more frequent in our CAR T cell cohort $(34.5 \%$ vs. $22 \%$ in the control group), which was probably due to a bias in selection of heavily pretreated $r / r$ DLBCL patients. On the other hand, our control group also consisted of $r / r$ DLBCL patients with at least two rituximab-containing therapy lines. However, TP53 mutated patients in the CAR T cell cohort trended towards worse outcomes compared with CAR T cell treated, TP53 unmutated ones. The loss of significance regarding OS in the TP53+ CAR T cell group ( $p=0.263$ vs. $p=0.005)$ was surprising. Control patients with TP53 mutations had a median OS of 12.55 months, while patients treated with anti-CD19 CAR T cells had an OS 2.5 times longer (30.88 months).

Although our study cohort was too small to draw definitive conclusions, our findings may contribute to the understanding of the biology of DLBCL and may aid in choosing the most promising treatment in every setting.

We conclude that screening for TP53 mutations in lymphomas might be important to identify potential non-responders to chemotherapeutic agents. In those cases, an early switch to therapy strategies using treatments with alternative mechanisms, such as CAR T cells, might help to improve prognosis.

We are conscious of the limitations of this study. As a retrospective analysis, the present study is prone to selection and reporting biases. Prospective randomized observational studies should be performed; however, ethical aspects must be considered. Further, the statistical power was limited due to the low sample size, especially of the CAR T cell cohort. The observation time was also still limited due to the novelty of CAR T-cell therapy and its limited availability in smaller centers. In the control group, only patients with positive p53 immunohistochemistry were further sequenced. Despite the reasonable and published correlation of p53 protein overexpression and TP53 mutation [17], it is possible that some TP53 mutated cases were missed in the control group. However, the number is expected to be low, also regarding the incidence of $22 \%$, which is in line with published data.

\section{Conclusions}

Despite all of the limitations of this study, this is one of the first studies showing the impact of TP53 mutation status on outcomes of patients treated with CAR T-cell therapy 
as opposed to conventional chemoimmunotherapy. Albeit in limited numbers (and only hypothesis generating), TP53 mutation status does not seem to affect outcomes in DLBCL patients treated with CAR T-cell therapy. Our data suggest that TP53 mutation analysis should be included when prognostic factors are evaluated before CAR T-cell treatment, because data regarding molecular prognostic markers of CAR T cell treated patients are very rare to date. The prognostic value of known genetic markers might be modified by novel therapies targeting other cellular mechanisms than cytotoxic agents. The rapid development of novel treatment strategies urges large multicenter studies comparing biomarkers for novel immunotherapies.

Supplementary Materials: The following are available online at https://www.mdpi.com/article/10 .3390 / cancers13225592/s1, Table S1: List of gene targets for detection of relevant SNVs, CNV, gene fusions and indels from 161 genes.

Author Contributions: Conceptualization, E.P., U.J. and A.-I.S.; formal analyses, E.P.; data curation, L.M., I.S.-K., C.K., J.R. and A.-I.S.; investigation, P.W., O.K., W.R., C.S., P.S. and N.W.; supervision: U.J.; writing-original draft preparation, E.P. and A.-I.S.; writing-review and editing, U.J., O.K., C.K., P.S. and I.S.-K. All authors have read and agreed to the published version of the manuscript.

Funding: This research received no external funding.

Institutional Review Board Statement: Ethical approval was granted by the Ethics Committee of the Medical University of Vienna (EK 1579/2018).

Informed Consent Statement: Informed consent was obtained from all subjects involved in the study.

Data Availability Statement: Data are contained within the article.

Conflicts of Interest: The authors declare no conflict of interest.

\section{References}

1. Schmitz, R.; Wright, G.W.; Huang, D.W.; Johnson, C.A.; Phelan, J.D.; Wang, J.Q.; Roulland, S.; Kasbekar, M.; Young, R.M.; Shaffer, A.L.; et al. Genetics and Pathogenesis of Diffuse Large B-Cell Lymphoma. N. Engl. J. Med. 2018, 378, 1396-1407. [CrossRef]

2. Miao, Y.; Medeiros, L.J.; Li, Y.; Li, J.; Young, K.H. Genetic alterations and their clinical implications in DLBCL. Nat. Rev. Clin. Oncol. 2019, 16, 634-652. [CrossRef]

3. Reddy, A.; Zhang, J.; Davis, N.S.; Moffitt, A.B.; Love, C.L.; Waldrop, A.; Leppa, S.; Pasanen, A.; Meriranta, L.; KarjalainenLindsberg, M.L.; et al. Genetic and Functional Drivers of Diffuse Large B Cell Lymphoma. Cell 2017, 171, 481-494.e415. [CrossRef]

4. Chapuy, B.; Stewart, C.; Dunford, A.J.; Kim, J.; Kamburov, A.; Redd, R.A.; Lawrence, M.S.; Roemer, M.G.M.; Li, A.J.; Ziepert, M.; et al. Molecular subtypes of diffuse large B cell lymphoma are associated with distinct pathogenic mechanisms and outcomes. Nat. Med. 2018, 24, 679-690. [CrossRef]

5. $\quad$ Bernard, E.; Nannya, Y.; Hasserjian, R.P.; Devlin, S.M.; Tuechler, H.; Medina-Martinez, J.S.; Yoshizato, T.; Shiozawa, Y.; Saiki, R.; Malcovati, L.; et al. Implications of TP53 allelic state for genome stability, clinical presentation and outcomes in myelodysplastic syndromes. Nat. Med. 2020, 26, 1549-1556. [CrossRef] [PubMed]

6. Huang, P.; Chen, S.; Yang, X.; Lei, Y.Y.; Xu, X.Y.; Liu, Y.X.; Guo, Y.H.; Pan, Y.; Wang, X.H.; Zhang, H.L.; et al. [Prognostic evaluation of P53 and BCL2 proteins in MYC/BCL2 double expression DLBCL]. Zhonghua Xue Ye Xue Za Zhi 2019, 40, 589-593. [CrossRef] [PubMed]

7. Pascual, M.; Mena-Varas, M.; Robles, E.F.; Garcia-Barchino, M.J.; Panizo, C.; Hervas-Stubbs, S.; Alignani, D.; Sagardoy, A.; Martinez-Ferrandis, J.I.; Bunting, K.L.; et al. PD-1/PD-L1 immune checkpoint and p53 loss facilitate tumor progression in activated B-cell diffuse large B-cell lymphomas. Blood 2019, 133, 2401-2412. [CrossRef] [PubMed]

8. Schiefer, A.I.; Kornauth, C.; Simonitsch-Klupp, I.; Skrabs, C.; Masel, E.K.; Streubel, B.; Vanura, K.; Walter, K.; Migschitz, B.; Stoiber, D.; et al. Impact of Single or Combined Genomic Alterations of TP53, MYC, and BCL2 on Survival of Patients With Diffuse Large B-Cell Lymphomas: A Retrospective Cohort Study. Medicine 2015, 94, e2388. [CrossRef] [PubMed]

9. Xu-Monette, Z.Y.; Wu, L.; Visco, C.; Tai, Y.C.; Tzankov, A.; Liu, W.M.; Montes-Moreno, S.; Dybkaer, K.; Chiu, A.; Orazi, A.; et al. Mutational profile and prognostic significance of TP53 in diffuse large B-cell lymphoma patients treated with R-CHOP: Report from an International DLBCL Rituximab-CHOP Consortium Program Study. Blood 2012, 120, 3986-3996. [CrossRef]

10. Morin, R.D.; Assouline, S.; Alcaide, M.; Mohajeri, A.; Johnston, R.L.; Chong, L.; Grewal, J.; Yu, S.; Fornika, D.; Bushell, K.; et al. Genetic Landscapes of Relapsed and Refractory Diffuse Large B-Cell Lymphomas. Clin. Cancer Res. Off. J. Am. Assoc. Cancer Res. 2016, 22, 2290-2300. [CrossRef]

11. Huang, Y.; Sadée, W. Membrane transporters and channels in chemoresistance and -sensitivity of tumor cells. Cancer Lett. 2006, 239, 168-182. [CrossRef] 
12. Marin, J.J.; Romero, M.R.; Martinez-Becerra, P.; Herraez, E.; Briz, O. Overview of the molecular bases of resistance to chemotherapy in liver and gastrointestinal tumours. Curr. Mol. Med. 2009, 9, 1108-1129. [CrossRef]

13. Hientz, K.; Mohr, A.; Bhakta-Guha, D.; Efferth, T. The role of p53 in cancer drug resistance and targeted chemotherapy. Oncotarget 2017, 8, 8921-8946. [CrossRef]

14. Intlekofer, A.M.; Joffe, E.; Batlevi, C.L.; Hilden, P.; He, J.; Seshan, V.E.; Zelenetz, A.D.; Palomba, M.L.; Moskowitz, C.H.; Portlock, C.; et al. Integrated DNA/RNA targeted genomic profiling of diffuse large B-cell lymphoma using a clinical assay. Blood Cancer J. 2018, 8, 60. [CrossRef] [PubMed]

15. Preudhomme, C.; Fenaux, P. The clinical significance of mutations of the P53 tumour suppressor gene in haematological malignancies. Br. J. Haematol. 1997, 98, 502-511. [CrossRef] [PubMed]

16. Simonitsch-Klupp, I.; Hauser, I.; Ott, G.; Drach, J.; Ackermann, J.; Kaufmann, J.; Weltermann, A.; Greinix, H.T.; Skrabs, C.; Dittrich, C.; et al. Diffuse large B-cell lymphomas with plasmablastic/plasmacytoid features are associated with TP53 deletions and poor clinical outcome. Leukemia 2004, 18, 146-155. [CrossRef] [PubMed]

17. Zenz, T.; Kreuz, M.; Fuge, M.; Klapper, W.; Horn, H.; Staiger, A.M.; Winter, D.; Helfrich, H.; Huellein, J.; Hansmann, M.L.; et al. TP53 mutation and survival in aggressive B cell lymphoma. Int. J. Cancer 2017, 141, 1381-1388. [CrossRef] [PubMed]

18. Sermer, D.; Batlevi, C.; Palomba, M.L.; Shah, G.; Lin, R.J.; Perales, M.A.; Scordo, M.; Dahi, P.; Pennisi, M.; Afuye, A.; et al. Outcomes in patients with DLBCL treated with commercial CAR T cells compared with alternate therapies. Blood Adv. 2020, 4, 4669-4678. [CrossRef] [PubMed]

19. Sermer, D.; Brentjens, R. CAR T-cell therapy: Full speed ahead. Hematol. Oncol. 2019, 37, 95-100. [CrossRef] [PubMed]

20. Locke, F.L.; Ghobadi, A.; Jacobson, C.A.; Miklos, D.B.; Lekakis, L.J.; Oluwole, O.O.; Lin, Y.; Braunschweig, I.; Hill, B.T.; Timmerman, J.M.; et al. Long-term safety and activity of axicabtagene ciloleucel in refractory large B-cell lymphoma (ZUMA-1): A single-arm, multicentre, phase 1-2 trial. Lancet Oncol. 2019, 20, 31-42. [CrossRef]

21. Hans, C.P.; Weisenburger, D.D.; Greiner, T.C.; Gascoyne, R.D.; Delabie, J.; Ott, G.; Müller-Hermelink, H.K.; Campo, E.; Braziel, R.M.; Jaffe, E.S.; et al. Confirmation of the molecular classification of diffuse large B-cell lymphoma by immunohistochemistry using a tissue microarray. Blood 2004, 103, 275-282. [CrossRef] [PubMed]

22. Swerdlow, S.H.; Campo, E.; Pileri, S.A.; Harris, N.L.; Stein, H.; Siebert, R.; Advani, R.; Ghielmini, M.; Salles, G.A.; Zelenetz, A.D.; et al. The 2016 revision of the World Health Organization classification of lymphoid neoplasms. Blood 2016, 127, 2375-2390. [CrossRef] [PubMed]

23. Green, T.M.; Young, K.H.; Visco, C.; Xu-Monette, Z.Y.; Orazi, A.; Go, R.S.; Nielsen, O.; Gadeberg, O.V.; Mourits-Andersen, T.; Frederiksen, M.; et al. Immunohistochemical double-hit score is a strong predictor of outcome in patients with diffuse large B-cell lymphoma treated with rituximab plus cyclophosphamide, doxorubicin, vincristine, and prednisone. J. Clin. Oncol. Off. J. Am. Soc. Clin. Oncol. 2012, 30, 3460-3467. [CrossRef] [PubMed]

24. Bouaoun, L.; Sonkin, D.; Ardin, M.; Hollstein, M.; Byrnes, G.; Zavadil, J.; Olivier, M. TP53 Variations in Human Cancers: New Lessons from the IARC TP53 Database and Genomics Data. Hum. Mutat. 2016, 37, 865-876. [CrossRef] [PubMed]

25. Aas, T.; Børresen, A.L.; Geisler, S.; Smith-Sørensen, B.; Johnsen, H.; Varhaug, J.E.; Akslen, L.A.; Lønning, P.E. Specific P53 mutations are associated with de novo resistance to doxorubicin in breast cancer patients. Nat. Med. 1996, 2, 811-814. [CrossRef] [PubMed]

26. Knappskog, S.; Chrisanthar, R.; Løkkevik, E.; Anker, G.; Østenstad, B.; Lundgren, S.; Risberg, T.; Mjaaland, I.; Leirvaag, B.; Miletic, H.; et al. Low expression levels of ATM may substitute for CHEK2/TP53 mutations predicting resistance towards anthracycline and mitomycin chemotherapy in breast cancer. Breast Cancer Res. BCR 2012, 14, R47. [CrossRef]

27. Geisler, S.; Lønning, P.E.; Aas, T.; Johnsen, H.; Fluge, O.; Haugen, D.F.; Lillehaug, J.R.; Akslen, L.A.; Børresen-Dale, A.L. Influence of TP53 gene alterations and c-erbB-2 expression on the response to treatment with doxorubicin in locally advanced breast cancer. Cancer Res. 2001, 61, 2505-2512.

28. Varna, M.; Bousquet, G.; Plassa, L.F.; Bertheau, P.; Janin, A. TP53 status and response to treatment in breast cancers. J. Biomed. Biotechnol. 2011, 2011, 284584. [CrossRef]

29. Bergamaschi, D.; Gasco, M.; Hiller, L.; Sullivan, A.; Syed, N.; Trigiante, G.; Yulug, I.; Merlano, M.; Numico, G.; Comino, A.; et al. p53 polymorphism influences response in cancer chemotherapy via modulation of p73-dependent apoptosis. Cancer Cell 2003, 3, 387-402. [CrossRef]

30. Minotti, G.; Menna, P.; Salvatorelli, E.; Cairo, G.; Gianni, L. Anthracyclines: Molecular advances and pharmacologic developments in antitumor activity and cardiotoxicity. Pharmacol. Rev. 2004, 56, 185-229. [CrossRef]

31. Lin, X.; Howell, S.B. DNA mismatch repair and p53 function are major determinants of the rate of development of cisplatin resistance. Mol. Cancer Ther. 2006, 5, 1239-1247. [CrossRef]

32. Gadducci, A.; Cosio, S.; Muraca, S.; Genazzani, A.R. Molecular mechanisms of apoptosis and chemosensitivity to platinum and paclitaxel in ovarian cancer: Biological data and clinical implications. Eur. J. Gynaecol. Oncol. 2002, 23, 390-396. [PubMed]

33. Rusch, V.; Klimstra, D.; Venkatraman, E.; Oliver, J.; Martini, N.; Gralla, R.; Kris, M.; Dmitrovsky, E. Aberrant p53 expression predicts clinical resistance to cisplatin-based chemotherapy in locally advanced non-small cell lung cancer. Cancer Res. 1995, 55, 5038-5042. [PubMed]

34. Tung, M.C.; Lin, P.L.; Wang, Y.C.; He, T.Y.; Lee, M.C.; Yeh, S.D.; Chen, C.Y.; Lee, H. Mutant p53 confers chemoresistance in non-small cell lung cancer by upregulating Nrf2. Oncotarget 2015, 6, 41692-41705. [CrossRef] [PubMed] 
35. Dhayat, S.A.; Mardin, W.A.; Seggewiß, J.; Ströse, A.J.; Matuszcak, C.; Hummel, R.; Senninger, N.; Mees, S.T.; Haier, J. MicroRNA Profiling Implies New Markers of Gemcitabine Chemoresistance in Mutant p53 Pancreatic Ductal Adenocarcinoma. PLoS ONE 2015, 10, e0143755. [CrossRef] [PubMed]

36. Fiorini, C.; Cordani, M.; Padroni, C.; Blandino, G.; Di Agostino, S.; Donadelli, M. Mutant p53 stimulates chemoresistance of pancreatic adenocarcinoma cells to gemcitabine. Biochim. Biophys. Acta 2015, 1853, 89-100. [CrossRef]

37. Galmarini, C.M.; Clarke, M.L.; Falette, N.; Puisieux, A.; Mackey, J.R.; Dumontet, C. Expression of a non-functional p53 affects the sensitivity of cancer cells to gemcitabine. Int. J. Cancer 2002, 97, 439-445. [CrossRef]

38. Sarkozy, C.; Sehn, L.H. Management of relapsed/refractory DLBCL. Best Pract. Res. Clin. Haematol. 2018, 31, 209-216. [CrossRef]

39. Gisselbrecht, C.; Van Den Neste, E. How I manage patients with relapsed/refractory diffuse large B cell lymphoma. Br. J. Haematol. 2018, 182, 633-643. [CrossRef]

40. Avanzi, M.P.; Yeku, O.; Li, X.; Wijewarnasuriya, D.P.; van Leeuwen, D.G.; Cheung, K.; Park, H.; Purdon, T.J.; Daniyan, A.F.; Spitzer, M.H.; et al. Engineered Tumor-Targeted T Cells Mediate Enhanced Anti-Tumor Efficacy Both Directly and through Activation of the Endogenous Immune System. Cell Rep. 2018, 23, 2130-2141. [CrossRef]

41. Yeku, O.O.; Purdon, T.J.; Koneru, M.; Spriggs, D.; Brentjens, R.J. Armored CAR T cells enhance antitumor efficacy and overcome the tumor microenvironment. Sci. Rep. 2017, 7, 10541. [CrossRef] [PubMed]

42. Kochenderfer, J.N.; Somerville, R.P.T.; Lu, T.; Shi, V.; Bot, A.; Rossi, J.; Xue, A.; Goff, S.L.; Yang, J.C.; Sherry, R.M.; et al. Lymphoma Remissions Caused by Anti-CD19 Chimeric Antigen Receptor T Cells Are Associated With High Serum Interleukin-15 Levels. J. Clin. Oncol. Off. J. Am. Soc. Clin. Oncol. 2017, 35, 1803-1813. [CrossRef] [PubMed]

43. Schuster, S.J.; Bishop, M.R.; Tam, C.S.; Waller, E.K.; Borchmann, P.; McGuirk, J.P.; Jäger, U.; Jaglowski, S.; Andreadis, C.; Westin, J.R.; et al. Tisagenlecleucel in Adult Relapsed or Refractory Diffuse Large B-Cell Lymphoma. N. Engl. J. Med. 2019, 380, 45-56. [CrossRef] [PubMed]

44. Zhang, X.; Lu, X.A.; Yang, J.; Zhang, G.; Li, J.; Song, L.; Su, Y.; Shi, Y.; Zhang, M.; He, J.; et al. Efficacy and safety of anti-CD19 CAR T-cell therapy in 110 patients with B-cell acute lymphoblastic leukemia with high-risk features. Blood Adv. 2020, 4, 2325-2338. [CrossRef]

45. Pan, J.; Tan, Y.; Deng, B.; Tong, C.; Hua, L.; Ling, Z.; Song, W.; Xu, J.; Duan, J.; Wang, Z.; et al. Frequent occurrence of CD19-negative relapse after CD19 CAR T and consolidation therapy in 14 TP53-mutated r/r B-ALL children. Leukemia 2020, 34, 3382-3387. [CrossRef]

46. Pan, J.; Niu, Q.; Deng, B.; Liu, S.; Wu, T.; Gao, Z.; Liu, Z.; Zhang, Y.; Qu, X.; Zhang, Y.; et al. CD22 CAR T-cell therapy in refractory or relapsed B acute lymphoblastic leukemia. Leukemia 2019, 33, 2854-2866. [CrossRef]

47. Pan, J.; Yang, J.F.; Deng, B.P.; Zhao, X.J.; Zhang, X.; Lin, Y.H.; Wu, Y.N.; Deng, Z.L.; Zhang, Y.L.; Liu, S.H.; et al. High efficacy and safety of low-dose CD19-directed CAR-T cell therapy in 51 refractory or relapsed B acute lymphoblastic leukemia patients. Leukemia 2017, 31, 2587-2593. [CrossRef]

48. Wang, M.; Munoz, J.; Goy, A.; Locke, F.L.; Jacobson, C.A.; Hill, B.T.; Timmerman, J.M.; Holmes, H.; Jaglowski, S.; Flinn, I.W.; et al. KTE-X19 CAR T-Cell Therapy in Relapsed or Refractory Mantle-Cell Lymphoma. N. Engl. J. Med. 2020, 382, 1331-1342. [CrossRef] 